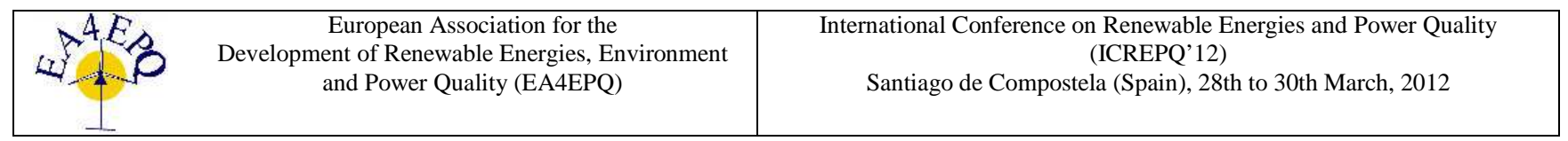

\title{
Developing a Platform for Energy Efficiency Monitoring
}

\author{
J. Lourenço ${ }^{1,2}$, N. Neves ${ }^{1,2}$, F. Reis ${ }^{2}$ and N. Valente ${ }^{2}$ \\ ${ }^{1}$ Research and Development Center \\ CIDISPGaya, Instituto Superior Politécnico Gaya \\ Avenida dos Descobrimentos, 333 - 4400-103 Santa Marinha - Vila Nova de Gaia (Portugal) \\ Phone/Fax number:+351 223745 730/1, e-mail: jml@ispgaya.pt, nneves@ispgaya.pt \\ ${ }^{2}$ Wideskills - Inovação, Projectos e Soluções, Lda. \\ Avenida dos Descobrimentos, 333 - 4400-103 Santa Marinha - Vila Nova de Gaia (Portugal) \\ Phone/Fax number:+351 223745 730/1, e-mail: nneves@ wideskills.pt
}

\begin{abstract}
.
This paper describes the R\&D project that CIDISPGaya and WideSkills are developing in the field of renewable energies and the support of monitoring technologies for efficiency improvement. The aim of the project is to develop a prototype that enables a ubiquos access to a set of functionalities in a conventional and renewable energy facility.
\end{abstract}

\section{Key words}

Renewable energies, Energy monitoring, Ubiquos monitoring, Energy efficiency.

\section{Introduction}

The areas of renewable energies among with an efficient use of energy are nowadays a big concern within our daily lives. Beyond all the economic aspects, a clean and efficient use of energy has become an important social responsibility for companies and also individuals. All around the world several programs and policies have been implemented in order to achieve an increasing reduction in the carbon monoxide footprint. This society movement among with the world dependency of fossil energy brought a new focus in the R\&D community [1].

The actual scenario among with the deregulation of power systems, also with the concern of more competitive, adjustable and efficient power generation opens a new window of opportunities for the massive use of renewable plants at the distribution level. The residential and commercial buildings consume a great amount of generated power all over the world. The construction of isolated renewable power systems is an important way to solve also the power supply problems in remote areas and islands.

Therefore, there exists a clear need for reduction of power consumption. The solution is therefore using efficient generation technologies, using local renewable energy generation solutions [2].

The R\&D center - CIDISPGaya among with its related company WideSkills, who aims to bring the R\&D developments into the industry has devoted its work in this field. A multi-disciplinary team that joins researchers from the renewable energies area, computing and communications field have formed a team that aims to bring to life the project of building a platform that able to collect, process, correlate all the information gathered from conventional and renewable energy plants.

The purpose is to develop new tools that could have ubiquos access, and manage to improve efficiency of those environments.

In a brief description, the platform will have the support of a server, who collects data from several energy places. The purpose is to have in real time access to the production of a renewable energy facility and also to the energy consumption of conventional plants. The data will be collected in each plant and transmitted with the support of a $3 \mathrm{G} / 4 \mathrm{G}$ network. Aspects like instant energy consumption or production, but also several alarms that could report any unusual condition will be take into consideration.

The core of our system - the server, will collect all the data, generate priority alarms if necessary, store and correlate all the gathered data. The fact that we will have relevant information correlated with the geographical position of the monitored facilities will able to map efficiency map for the renewable energies efficiency versus its geographic position.

This research work aims to lead our team in an interdisciplinary cooperation for the developing of new solutions that could and should be brought to market, always with the focus of using the renewable solution as the solution for the energy efficiency concern.

The most relevant functionalities are summarized in Table 1. 


\begin{tabular}{|c|l|}
\hline Functionalities & \multicolumn{1}{c|}{ Goal } \\
\hline Main task & $\begin{array}{l}\text { Focus on the instant } \\
\text { energy generation } \\
\text { and consumption. }\end{array}$ \\
\hline Reports & $\begin{array}{l}\text { Production and/or } \\
\text { consumption of the } \\
\text { plant }\end{array}$ \\
\hline Alarms & $\begin{array}{l}\text { Report malfunction } \\
\text { such as usual } \\
\text { consumption or } \\
\text { unusual decrease of } \\
\text { renewable energy } \\
\text { production }\end{array}$ \\
\hline Technology & $\begin{array}{l}\text { Server, Local } \\
\text { Processing Unit and } \\
\text { 3G/4G link. }\end{array}$ \\
\hline $\begin{array}{c}\text { Service } \\
\text { provided }\end{array}$ & $\begin{array}{l}\text { Ubiquos access to } \\
\text { an secure webpage } \\
\text { with all the } \\
\text { gathered } \\
\text { information. }\end{array}$ \\
\hline
\end{tabular}

Table 1

\section{Market and Business Model}

This platform will be an important tool for a real time analysis of several types of energy facilities. The ability to retrieve this information as quickly as possible will improve overall efficiency, by reducing down time and understanding the best spots to install a new energy plant. As described in the previous section, among the social responsibility aspect, we have the experienced several contacts about renewable energies hardware developers and maintenance teams that need a quick access to the energy plan status, in order to implement fast technical interventions. This procedure brings relevant efficiency gains in the process. On the other hand, having access to the instaneous consumption of a facility, and doing an analysis with historical data, can help to understand if there are any possibilities for an optimization in the process.

After an initial process of a simple installation, the service will be supported by a monthly fee, depending on the number of monitored facilities that the client plans to have access.

\section{Proposed Architecture and Layering}

The proposed architecture is briefly described:

\section{Hardware Description}

The main goal of the project is to implement a modular structure that could provide ease installation and also a special concern on the final cost of implementation. All the blocks involved are described in this section:

\section{A. Interfacing to the Plant}

The ideal point of measure is the output of the inverter of the installation. So, a careful design of all the market solutions was necessary. The most common interface presented is RS232 and a reduced number of solutions have an USB support.

The prototype will support both solution and can be configured to a different form of access.

\section{B. Local Processing and Communication}

The local processing involves, after the interfacing to the inverter, acquiring the data provided by the inverter. The main goal is to get an instant measure of the instaneous delivered power. The collected data should be locally processed in order to translate the inverter stream format to an intelligible measure. The data will be stored locally, and with an appropriate scheduling algorithm will be dispatched to the main server.

The described functionalities require a minimum hardware. The implemented solution for initial testing is supported by a mini-ITX module, running a Linux OS with a script running PHP and Java.

All the data will be send with the support of a $3 \mathrm{G} / 4 \mathrm{G}$ module.

In order to move into a scalable solution, it should be implemented a scheduling routine for the communication management concerns.

As long as the module described in this section supports the acquisition and communication protocol implemented the architectural approach is hardware and software agnostic.

Finally, after the prototyping phase the system will be also designed in order to have also a renewable power source to support its operation.

\section{Server Approach}

The solution proposed involves a central server. This server will collect the data from several plants, generate alarms for malfunction issues, implement a statistical analysis and enable a friendly interface to all the customers that use the service. In the actual trial tests that we are conducting a Linux server from ISPGaya was allocated to this purpose.

Scalability and the central server approach should mean a shift into a distributed server solution, in order to avoid the bottleneck of a single server processing all the data collected.

\section{Ubiquos Access}

All the processed data will be accessed through any kind of Internet access device. The client side software will be developed in order to provide a secure access. In the prototype version two different supports will be provided an Android application and a HTML5 site, in order to provide a universal and ubiquos access.

The provided application will provide access to the instantaneous power generation, graphical perspective of the evolution of the generated power and failure alarms. The final product will have a SMS support in order to implement a real-time communications for critical malfunctions. 
All the described functionalities are supported by the main server that deals with all the requests from final clients of the platform.

\section{Further Research and Developments}

As previously discussed in previous section, it can be defined a cluster of companies that provide support and maintenance in the renewable energies and efficient use of energy that had shown interest in the development of the proposed platform. Beyond our interest in mapping the renewable energy efficiency distribution nationwide, in order to understand which geographic points provide the best spot for the installation of a new energy facility. Several industry contacts suggest the strong possibility of a national implementation of the final prototype. An important nationwide database will be built, enabling a detailed and constructive analysis of the efficiency of each different type of renewable source, always correlated to the geographical position. The rich scenario of several types of renewable sources of energy implemented in Portugal will for sure granted relevant results [4],[5].

The proposed prototype will provide further features that could lead our research study. As an example, another focus of our work will be to understand all the issues related to the efficiency of different renewable sources placed at the same spot and also develop a new prototype that with the same principles will able a monitoring of the power consumption in the final consumers.

\section{Trial Test Results}

The proposed solution in this article was implemented for the trial tests. The current test is being conducted in the renewable energy facilities at ISPGaya, with two different local processing and acquisition units with the configurations detailed in section 4 .

The local server besides the acquisition of the required instantaneous measure also broadcast its geographic position to the main server.

Our research team is also focused in starting the nationwide diffusion of the proposed solutions in order to start the desired nationwide data collection.

\section{Conclusions}

This paper plans to make a brief description of all the recent work in the field of renewable sources of energy that has been conducted in CIDISPGaya. As previously stated, the work of several teams with different fields of research was relevant to this prototype conception.

We are conducting the final developing and testing in order to start collecting the initial data.

Some special concern was taking into account when studying the ideal statistical tools to analyse the data. The relevance of the link between the data and the geographical spot was also considered of special relevance.

Several companies have shown there interest on having such a powerful tool of analysis in their portfolio.

\section{References}

[1] M. Zhan and Y. Yang, "On Analysis of Suggestions on the Development of China's Renewable Energy Industry Based on 'Low-Carbon Economy' ”, 2010 International Conference on in Management and Service Science (MASS), pp. 1-4.

[2] H.F. Wedde, S. Lehnhoff, E. Handschin and O. Krause, "Establishing Large-Scale Renewable Reserve Capacity through Distributed Multi-Agent Support", in 2007 5th IEEE International Conference on Industrial Informatics, Vol. 2, pp. $1157-1163$.

[3] C. Jian, C. Yanbo and Z. Jijie, "Optimal configuration and analysis of isolated renewable power systems", 2011 4th International Conference on Power Electronics Systems and Applications (PESA), pp. 1 - 4 .

[4] P.K. Lee and L.L. Lai, "A practical approach of smart metering in remote monitoring of renewable energy applications", in PES '09. IEEE Power \& Energy Society General Meeting 2009, pp. 1 - 4.

[5] A. Hadian, M.R. Haghifam, J. Zohrevand, E. AkhavanRezai, "Probabilistic approach for renewable dg placement in distribution systems with uncertain and time varying loads", in PES '09. IEEE Power \& Energy Society General Meeting, 2009, pp 1-8. 